\title{
XI
}

\section{ASSISTENNCIA SOCIAL E CONSERVADORISMO: DILEMAS E RESISTÊNCIAS DO EXERCÍCIO PROFISSIONAL DE ASSISTENTES SOCIAIS DIANTE DA PANDEMIA DA COVID-19*}

\author{
Ana Paula Cardoso \\ Ana Paula Mauriel \\ Mossicleia Mendes da Silva
}

\section{Introdução}

O presente texto tem como objetivo realizar um balanço inicial acerca do exercício profissional de assistentes sociais trabalhadores da política de assistência social no estado do Rio de Janeiro, no contexto da pandemia da Covid19, problematizando a ofensiva conservadora em curso, a crise capitalista, aprofundada pelas medidas de contingenciamento da crise sanitária e os desafios e resistências colocados aos profissionais de Serviço Social.

Para tanto, organizamos as reflexões em duas seções, além desta introdução e das considerações finais. Na primeira, trazemos um eixo de análise de escopo mais aberto que visa articular o debate entre a crise do capital, o avanço do conservadorismo sobre a política de assistência social e os aspectos mais conjunturais relativos à pandemia. A primeira subseção trata dos rebatimentos da escalada conservadora sobre o exercício profissional no âmbito do Sistema Único de Assistência Social (SUAS); a segunda faz uma problematização sobre as implicações da crise capitalista com a crise sanitária e os rebatimentos sobre o SUAS que, em função do desmonte e desfinanciamento dos últimos anos, enfrenta gargalos cruciais para atender às demandas postas pela sociedade, insufladas pelo alastramento do Novo Coronavírus.

$\mathrm{Na}$ última seção, trazemos aspectos da realidade do estado do Rio de Janeiro, apresentando e analisando os principais dilemas, desafios e resistências

* DOI - 10.29388/978-65-86678-40-6-0-f.317-340 
de assistentes sociais trabalhadores da política em questão, tanto da proteção social básica, como da proteção social especial do SUAS. As reflexões dessa seção apontam para o recrudescimento da precarização do trabalho, acentuadas sob as condições de insalubridade perante os riscos sanitários, da negligência e ingerência do Estado (nas instâncias da União, estados e municípios) no enfrentamento à pandemia e garantia de condições básicas para o exercício profissional seguro e a ofensiva conservadora que se espraia na gestão e operacionalização desta política no contexto atual.

\section{Crise, pandemia e avanço do conservadorismo na política de assistência social}

Diante do agravamento da crise após 2008 e das respostas dada a ela, percebe-se um processo de avanço acelerado do conservadorismo em todos os campos - ético, político, religioso, cultural, educacional, moral. Contudo, o conservadorismo nunca deixou de franquear a formação e o exercício profissional, ainda mais quando se trata da política de Assistência Social, cujo passado caracterizado pelo clientelismo, pelo patrimonialismo, pelo engessamento burocrático, pela cultura do favor, aparece reatualizado, potencializado sob novas contradições.

Para Escorsim Netto (2011), o conservadorismo em sua forma clássica continua marcando suas formas de manifestação contemporâneas, pois funciona como peça-chave fundamental na reprodução das relações sociais capitalistas, nunca saindo de cena, sendo necessário para conservar as bases da sociedade capitalista e sempre se colocando a seu dispor.

O conservadorismo clássico moderno, longe de se definir como um retrocesso puro e simples, sendo contra todo tipo de mudança e progresso, mostra-se compatível com transformações, porém sem rupturas com a ordem social (POGGI, 2019).

Diante dessa perspectiva, entendemos que as manifestações da extrema direita que vão ganhando corpo no Brasil não devem ser vistas como algo "fora do lugar e do tempo", como um fenômeno totalmente novo na atual conjuntura, até porque o que é novo no conservadorismo hoje não pode ser entendido por si mesmo, mas como expressão da atual configuração da luta de classes e das lutas dos/as oprimidos/as (IASI, 2015). 
O terreno no qual essas lutas ocorrem e sua configuração deita raízes nas relações sociais de produção e de propriedade determinantes desse momento histórico, momento de ofensiva da classe dominante no âmbito nacional e internacional.

Segundo Lowy (2015), alguns fatores ajudaram no sucesso da crescente ofensiva da extrema direita no cenário europeu, mas que poderíamos ampliar para o plano internacional: as respostas dadas à crise de 2008, que têm favorecido muito mais politicamente setores mais reacionários do que partidos e movimentos de centro ou à esquerda; o processo de globalização neoliberal financeirizada, o qual, além de provocar um processo de homogeneização cultural, ajudou a reforçar o fundamentalismo e o nacionalismo religioso; elementos culturais tradicionais históricos antissemitas e a cultura colonial que persistiu mesmo após a descolonização.

No Brasil, segundo Braz (2017), a ascensão de um conservadorismo reacionário no contexto recente brasileiro está ligada ao manejo da crise por parte da classe dominante, que não via mais no projeto de conciliação de classes uma forma compatível de gestão dos interesses do grande capital.

Daí que, mesmo com todas as medidas austeras realizadas, a ofensiva ultraneoliberal avançou contra o governo Dilma desde o início de 2013, obtendo sua primeira grande vitória com o impeachment, mas que não parou por aí, sendo uma porta para novos recuos democráticos e na desestruturação de direitos, como vemos com o que se seguiu com o governo Temer e com o atual presidente Jair Bolsonaro.

Nessa ofensiva está a funcionalidade e o sentido da "nova" direita, que é pressionar para a adoção de medidas cada vez mais duras contra os direitos dos trabalhadores/as e os serviços públicos, aprofundando a saída recessiva da crise (HOEVELLER, 2016).

A partir do golpe de 2016, o Brasil iniciou uma fase mais dramática do neoliberalismo, o que não apaga a gravidade dos processos iniciais de implantação e posterior consolidação do projeto das classes dominantes rentistas no nosso país (CASTELO, 2017). Desde então, observa-se um acelerado aumento da coerção estatal (atitudes violentas e repressivas) exercida contra trabalhadoras e trabalhadores, ganhando ares neofascistas, confirmando que o golpe que levou Michel Temer ao poder tem uma função histórica de retomar, a qualquer custo, as taxas de lucro declinantes no país e de silenciar coercitivamente os crescentes rompantes de rebeldia popular (greves operárias e de servidores pú- 
blicos, ocupações estudantis, urbanas e rurais, levantes indígenas, as lutas dos movimentos feminista, negro e LGBTQIA+, etc).

É nesse sentido que Braz (2017) afirma que as formas bonapartistas não clássicas vão se mostrar úteis, pois configuram formas políticas não abertamente ditatoriais, mas que conspiram contra qualquer avanço democrático, mesmo o burguês e qualquer avanço trabalhista, social conquistado pelos/as trabalhadores/as. Para o autor, tal forma política não é exatamente uma forma abertamente fascista, mas se vale de elementos fascistas, de uma cultura política fascista de ataque aos direitos (BRAZ, 2017).

Alimentado pelo golpe de 2016, o avanço da extrema direita, capitaneado pela burguesia e parcelas da classe média levou à eleição, em 2018, do atual presidente Jair Bolsonaro, um governo ultraneoliberal na economia, conservador e reacionário no social, nos valores e costumes e crescentemente autoritário na política e na perseguição às lutas sociais, com avanço ainda mais acelerado da ofensiva contra os direitos sociais.

Suas ações têm se dirigido à criminalização dos movimentos sociais que lutam e resistem e em perseguições do pensamento crítico e da produção de conhecimento, que possa revelar qualquer traço que questione a visão de mundo conservadora que o seu atual governo quer impor. As Universidades e Institutos Federais têm sido os principais alvos, pois além de sofrerem com as instabilidades dos contingenciamentos, cortes de bolsas e auxílios, são altamente atacadas pelo "Future-se". O ataque às universidades expressa também o desprezo que este governo possui em relação à importância da ciência.

Temos visto também as investidas constantes do governo Bolsonaro sobre as lutas contra as opressões, a exaltação do machismo, da homofobia, do racismo, dentre outras opressões - o que tem significado o aumento da violência de todo tipo na vida cotidiana. Além das ações de descaso com o meio ambiente e de facilitação para o ataque às áreas de proteção ambiental e reservas indígenas.

Diante de uma crise econômica, social e política de tais proporções, potencializada pela pandemia, onde se encara o risco de morte, a humanidade se questiona sobre as alternativas possíveis e que tipo de vida se quer, qual mundo se quer construir. Com isso, as saídas cientificamente ancoradas que afirmem o bem-estar das maiorias trabalhadoras podem pôr em questão modos de dominação e projetos de governo baseados em altos graus de exploração da força de trabalho, como o do atual governo ultraneoliberal e de tendências fascistas de Jair Bolsonaro. 
Como nos aponta Iasi (2015), a fantasia ideológica supõe que as pessoas tecem uma ideia que lhe serve de mediação entre elas e a realidade objetiva, não como uma mera falsidade, mas como uma ilusão necessária. Ou seja, não é simplesmente inventar uma mentira, mas viver uma mentira como se fosse verdade, levando-a a sério. E é isso que o governo vem fazendo durante a pandemia.

Assim, para se recompor a fantasia ideológica necessária ao bom funcionamento do mercado, é necessário excluir do campo de possibilidades algumas alternativas onde o processo revolucionário e de grandes transformações sociais para o bem-estar das maiorias aparece como um mundo possível. A questão é que, como em todo discurso ideológico, é necessário incluir a base real para depois deformá-la.

É nesse sentido que o fundamentalismo religioso, o conservadorismo e o reacionarismo se movem para delimitar o campo do possível desse governo, ou seja, uma política de morte via "seleção natural" dos mais fortes, negando e distorcendo o que é científico, obscurecendo as contribuições artísticas, culturais, intelectuais que podem questionar os limites dessa manipulação.

Diante desse governo que parece seguir defendendo os lucros e o bem-estar do capital acima de qualquer outra vida, utilizando caminhos cada vez mais autoritários, uma das questões fundamentais para a defesa da vida de trabalhadoras e trabalhadores é a luta por proteção social ou o que ainda resta dela, particularmente aqui passa pela não destruição da assistência social como política pública.

Desde a implementação do SUAS, em 2005, novos desdobramentos se colocaram para o trabalho profissional de assistentes sociais, com atribuições e competências em diferentes espaços e com diversas orientações legais e normatizações. Os assistentes sociais que atuam hoje na política de Assistência Social são atingidos diretamente por novas contradições em suas relações e condições de trabalho, em sua rotina com as equipes, nas relações com os usuários (SILVA; MAURIEL, 2019).

Mesmo com a Normal Operacional Básica - NOB/RH 2006, a qual demarca a contratação via concursos públicos, essa condição ainda não é garantida para a maioria dos profissionais. É comum encontrar profissionais concursados convivendo com outros servidores com contratos precários, sem os mesmos direitos trabalhistas e por tempo determinado ou por cargos comissionados, o que compromete a continuidade das ações. Tais condições vêm dificultando o planejamento e impõem uma rotinização estranha ao profissional, que 
é capturado pela rotina de atendimentos e demandas, sem poder refletir, planejar e sistematizar seu trabalho junto com seus pares e outros profissionais, dificultando atender às demandas de usuários para além do imediato.

Segundo Guerra (2010), tal fragmentação e descontinuidade do trabalho não permitem a apreensão do processo no qual o exercício profissional se realiza, limitando o conhecimento da totalidade aos elementos que constituem a situação, fazendo com que aquilo que se manifesta no cotidiano da vida dos usuários fique no plano singular e imediato. Com isso, no cotidiano profissional, dadas as suas características estruturadoras conservadoras atuais, a tendência é de considerar a intervenção pelo seu resultado, sem buscar os seus fundamentos e de realizar intervenções que concebam o indivíduo isolado da estrutura e do contexto sócio-histórico, de modo a responsabilizá-lo e, mais ainda, a culpabilizá-lo pelo seu suposto sucesso ou fracasso.

Não é circunstancial que apareçam novas demandas de intervenções pontuais, autonomizadas e isoladas junto às famílias, práticas terapêuticas, ações de responsabilidade individual e/ou social, requisições de práticas clínicas. E isso não está posto exclusivamente nas diretrizes da Política de Assistência Social, mas advém de processos sociais, políticos, econômicos que a envolvem e aos profissionais que nela exercem seu trabalho (SILVA; MAURIEL, 2019).

Considerando as recentes mudanças que caracterizam a esfera da produção e o mundo do trabalho, as quais trazem modificações do emprego estrutural, caracterizadas pela flexibilização produtiva, pela segmentação dos trabalhadores em estruturas ocupacionais cada vez mais complexas e a expansão dos serviços, assistentes sociais são submetidos a constrangimentos diante dos processos de intensificação e precarização do trabalho nos espaços institucionais onde realizam seu trabalho (YAZBEK, 2014).

Ademais, o conservadorismo tem se apresentado nas condições de formação profissional, haja vista que temos testemunhado como a educação superior vem sendo pressionada na direção da privatização, com currículos se flexibilizando em função dos mercados, com a Universidade cada vez mais centrada em uma perspectiva tecnocrática a partir de normas e critérios fundados em relações de custo-benefício, eficácia-inoperância, produtividade/improdutividade, sob forte interferência dos organismos multilaterais (YAZBEK, 2014).

Silveira Jr. (2016) aponta que tais tendências se encontram presentes nas noções, ideias e formas de racionalidade presentes na PNAS/SUAS. E suas fontes teóricas originárias, de onde partem as vertentes ideológicas conservadoras predominantes nos conteúdos e nos processos pedagógicos de capacitação 
da PNAS/SUAS, encontram-se nos organismos multilaterais ou financeiros historicamente atrelados às estratégias de restauração do capital.

Segundo Silveira Jr. (2016), é possível identificar três principais rebatimentos dessas tendências conservadoras na Política de Assistência. O primeiro está na forma de explicar as contradições e desigualdades sociais, que não são entendidas pelos seus determinantes estruturais, mas como uma questão de distribuição da riqueza ou uma má distribuição de renda. Em relação à assistência social, isso significa a centralidade da defesa dos programas de transferência de renda como estratégia prioritária. O segundo aspecto trata da visão do Estado, visto em abstrato e sem antagonismos de classe, o que dá força à ideia de aperfeiçoamento das superestruturas institucionais, dos arranjos técnico-gerenciais das políticas sociais em geral, e da gestão da assistência social em particular; o terceiro elemento está na própria concepção de assistência social, que aparece ligada ao fenômeno da pobreza identificada como "privação de capacidades individuais", e tal condição rotulada como "situação de risco e vulnerabilidade social".

Essa alteração tem impacto mais profundo no deslocamento da concepção e dos propósitos colocados para a assistência social, particularmente quando observamos o aumento do público-alvo da assistência social, que passa a ser integrado por uma massa crescente de trabalhadores(as) precários(as) e superexplorados(as), além de desempregados(as) aptos para o trabalho. Aqui as referidas ideologias passam a funcionar como formas de construção de consentimento dos mesmos para sua inserção subordinada no mercado precário da força de trabalho.

\section{Pandemia e política de assistência social: crise sanitária e o SUAS}

A identificação do Novo Coronavírus e sua doença, a COVID-19, provocou uma espécie de abalo sísmico no mundo, na alvorada do ano 2020. Entre o alerta da China à OMS sobre o surto de uma nova variante do vírus corona e a decretação de crise sanitária global foram questão de dias. O que se sucedeu à consolidação de uma das mais graves pandemias vivenciadas pela humanidade, com um nível de contaminação altíssimo e o colapso de vários sistemas de saúde mundo a fora. Além disso, os planos de contingência passavam inexoravelmente pela adoção de medidas duras de isolamento social. 
Não demorou muito para que a crise sanitária assumisse, na narrativa da grande mídia e da classe dominante global, a condição de fator cataclísmico causador de uma grave crise econômica mundial, que jogaria por terra as previsões para os PIBs das superpotências aos países periféricos. Como todo fenômeno comporta aparência e essência, é verídico que as medidas de isolamento social paralisaram importante parte da produção e circulação capitalista de mercadorias - produtos e serviços - brecando o circuito de valorização do capital em escala global. É evidente que tal situação cria problemas de grande magnitude para o capital, que não pode produzir valor sem exploração da força de trabalho, convergindo para a explosão da crise. No entanto, não é a pandemia a causadora da crise como querem fazer crer os apologetas do capital.

Por mais que tenha efeitos potencializadores, a crise sanitária não determina a crise econômica. A crise é capitalista, conforme demonstra a crítica da economia política marxista de um hemisfério ao outro do mundo. Gouvêa (2020) apresenta teses centrais que nos auxiliam nessa compreensão. A primeira é que não é verdade que a economia mundial vinha se recuperando e que a fatalidade da pandemia precipitou uma nova derrocada. Desde 2018, pelo menos uma nova onda da crise de 2008 estava em curso, acirrada pelas disputas geopolíticas entre China e EUA; na segunda hipótese, a autora explica que "[...] mesmo considerando que a dimensão disruptiva da crise já em curso se alterou qualitativamente com a emergência da pandemia" (GOUVÊEA, 2020, p. 21) é fundamental explicitar que a deflagração de doenças como a Covid-19 não existira fora do modo de produção capitalista e, tampouco, seus efeitos seriam os mesmos em outra forma de sociabilidade e produção da vida. $\mathrm{O}$ terceiro argumento demonstra que, de fato, o isolamento exigido para contingenciamento da doença impõe o aprofundamento da crise em escalas nunca vistas.

No Brasil, os efeitos da pandemia foram potencializados pela ingerência e irresponsabilidade do governo federal com seus fundamentos irracionais, anticientíficos e terraplanistas, com, pelo menos, três mudanças de ministro da saúde, estando agora este ministério a carga de um general. O quadro epidemiológico é desolador e no momento em que produzimos este texto, o Brasil tem mais de 140 mil mortes (outubro de 2020), sem contar o nível alto de subnotificação perpetrado pela lógica negacionista que direciona a gestão da pandemia no Brasil.

No quadro dramático do capitalismo dependente brasileiro, a crise sanitária exponenciou as condições alarmantes de desemprego, pobreza, insalubridade e precarização das condições de vida da classe trabalhadora. Sob a bali- 
za de um governo de extrema direita, a política econômica ultraneoliberal encabeçada pelo ministro Paulo Guedes vem, desde 2019, promovendo uma ofensiva destrutiva sobre os direitos sociais, desestruturando políticas públicas, privatizando serviços e empresas ou segmentos estatais na esteira de contrarreformas como a da previdência social.

É nesse contexto de "terra arrasada" que as consequências de uma crise sanitária com as características que vivenciamos tornam-se trágicas para os segmentos mais empobrecidos da classe trabalhadora, sobretudo os mais precarizados e/ou aqueles sob as condições aviltantes do fenômeno da "uberização do trabalho" (ANTUNES, 2020).

Pouco tempo depois da confirmação do primeiro caso do novo coronavírus no Brasil, em fins de fevereiro, o governo federal decretou "estado de calamidade pública" que, ao determinar a paralisação de algumas atividades para viabilizar o isolamento social, elencava os serviços considerados essenciais, entre os quais constavam a "assistência social e o atendimento à população em situação de vulnerabilidade”, conforme Decreto Presidencial no 10.282/2020.

Intervir sobre contexto de calamidade pública não seria uma novidade para a política de assistência social, uma vez que a própria Tipificação Nacional dos Serviços Socioassistenciais, aprovada em 2009, já determinava que os serviços da Proteção Social Especial, sobretudo de alta complexidade, seriam considerados essenciais em contextos de calamidade pública e emergência. No entanto, é estranho à política de assistência social brasileira o envolvimento de seus serviços em uma crise desse porte e passamos a observar um movimento que beirava ao caos para que o Sistema Único de Assistência Social (SUAS), que já vinha padecendo da ofensiva ultraneoliberal que engendra seu desfinanciamento e desmantelamento, pudesse dar conta das demandas insulfladas pela crise sanitária, em um contexto onde as expressões da questão social já eram extremamente acirradas.

As mais profundas mazelas do capitalismo dependente brasileiro expõem, então, sem nenhuma camuflagem, o contingente de trabalhadores em trabalho informal e sem garantias trabalhistas, a pobreza absoluta de pessoas que sobrevivem, através das atividades mais precárias, instáveis e espoliativas, a fragilidade de rendimentos de indivíduos que sobrevivem da autoexploração intensiva e de seus familiares, glamourizados sob o mantra do empreendedorismo, terceirizados, artistas, pequenos comerciantes, vendedores ambulantes, trabalhadoras domésticas, trabalhadores de aplicativos de toda sorte e uma miríade de tantos outros que compõem o fenômeno da uberização do trabalho. 
A Pandemia desvela a própria barbarização da vida que o capitalismo opera na tentativa de garantir sua reprodução ampliada, mas como afeta - ainda que não da mesma forma - setores médios e altos da burguesia - a crise sanitária requer do Estado e da sociedade medidas que possam mitigar os estragos mais nefastos. A política de assistência social que vem, no Brasil, assumindo funcionalidade nos últimos anos para dar conta de demandas da reprodução da classe trabalhadora, sobretudo sua fração mais empobrecida ou, para usar termos do Marx, aquele contingente que compõe a superpopulação relativa estagnada (MARX, 2013), é requisitada a intensificar suas ações (SILVA, 2020).

Mesmo em face da gravidade da situação e da instrumentalidade que a assistência social pode ter para gerenciar expressões mais disruptivas da questão social, as medidas de proteção social foram objetos de retardo proposital por porta do governo federal. ${ }^{1}$

Passado quase um mês da decretação de calamidade pública, em face do aprofundamento do desastre social e da intensificação da pressão pública por parte de governadores, prefeitos, secretários estaduais e municipais de assistência social, bem como, de trabalhadores e seus fóruns organizativos, além dos próprios usuários, o Ministério da Cidadania começa uma "correria" para garantir medidas de contingenciamento da pandemia e passa a tentar "remediar" em dias, o estrago dos últimos quatro (4) anos, permitindo, por exemplo, o uso de saldos de contas dos Fundos Municipais de Assistência Social e flexibilizando a alocação dos recursos para facilitar compra de suprimentos e Equipamentos de Proteção Individual (EPIs) (PORTARIA CONJUNTA No 1 /2020, MINISTÉRIO DA CIDADANIA).

Em 16 de abril, o Governo Federal editou a Medida Provisória n ${ }^{\circ}$ 953, designando um Crédito Extraordinário para o Ministério da Cidadania com vistas ao Enfrentamento do Novo Coronavírus, no valor de R 2,550 bilhões. De acordo com a Secretaria Nacional de Assistência Social (SNAS), ${ }^{2}$ o recurso poderia ser aplicado tanto na Proteção Social Básica (PSB) como na Proteção Social Especial (PSE), podendo ser usado na contratação de pessoal, no pagamen-

\footnotetext{
${ }^{1}$ No dia 18/3/2020, o governo anuncia medidas em diferentes ministérios e áreas (Economia, Infraestrutura, Justiça, Relações Exteriores, Desenvolvimento Regional, Saúde, Defesa e Anvisa), mas sequer uma palavra sobre as medidas do Ministério da Cidadania que abarca, dentre outras áreas, a Secretaria Nacional de Assistência Social e a Secretaria Nacional de Renda de Cidadania. Tal postura já indicava preocupação com as áreas da economia e da saúde e total desprezo com o sofrimento de milhares de brasileiros marcados pela insuficiência de renda para a sobrevivência e proteção (LOPES; RIZZOTTI, 2020, p. 134).

2 Em live no Canal da Conferência Nacional de Municípios, no youtube no dia 17/04/2020.Disponível em: <https://www.youtube.com/watch?v=g9V4sE_YwhE >.
} 
to de alimentação complementar de usuários e equipes, pagamentos de serviços de terceiros, incremento aos benefícios eventuais, como contratos funerários (sic), contratação de cuidadores, gasto com custeio, comprar EPIs, contratação de serviço de comunicação, melhorar e adequar infraestrutura para garantias de segurança quanto ao contágio, equipamentos de ventilação, eletrônicos, ampliação ou instalação de rede de internet, etc. A prioridade inicial seria para melhorias nas unidades de acolhimento, públicas ou da rede conveniada, dando ênfase às situações decorrentes da população em situação de rua. A transferência de início se dará mediante ranqueamento, em função da quantidade de pessoas em situação de rua nos municípios.

Apenas em fins de abril, o Ministério da Cidadania publicou a Portaria $\mathrm{n}^{\circ} 369$, dispondo sobre o repasse financeiro emergencial desse recurso para a execução de ações socioassistenciais e estruturação da rede do SUAS. A Portaria elenca um rol de condicionalidades e métodos para cálculos e definições dos recursos a serem aportados em cada município ou estado, conforme seu porte e em função da quantidade de trabalhadores em exercício, de usuários a serem atendidos, de vagas de acolhimento, de modalidade de serviço. Há a determinação, inclusive do valor-base para cálculo. Por exemplo, os valores de referência para estruturação da rede quanto à aquisição de: "EPI, observará o valor de referência de R \$ 175,00 (cento e setenta e cinco reais) mensal por trabalhador, multiplicado pelo quantitativo de trabalhadores a serem contemplados"; quanto à alimentação, o valor base é " $\mathrm{R} \$ 115,00$ (cento e quinze reais) mensal por pessoa, multiplicado pelo quantitativo de pessoas a serem contempladas".

A portaria ainda enfatiza que "[...] a segunda parcela referente ao inciso I do $₫ 1^{\circ}$ estará condicionada à real necessidade de uso de EPI, de acordo com as recomendações do Ministério da Saúde - MS, conforme ato complementar da SNAS" (PORTARIA No 369/2020, MINISTÉRIO DA CIDADANIA). Mesmo considerando que a burocracia tem uma base instrumental para dificultar o acesso a direitos, e que a fórmula do menor custo-benefício está na base de toda ação do Estado capitalista no cerne da radicalização neoliberal, asseverar a comprovação de "real necessidade de uso de EPIs" no contexto de uma pandemia demonstra o nível de tecnicismo, minimalismo e até mesmo irracionalismo a que chegaram as medidas de proteção social no Brasil.

Além de especificar as metas físicas, os municípios e estados deveriam firmar Termo de Aceite, apresentar Plano de Ação e os procedimentos de prestação de contas. Os recursos devem ser disponibilizados em duas parcelas, cada uma relacionada a três (3) meses de atendimento, "observada a disponibilidade 
orçamentária e financeira" (PORTARIA No 369/2020, MINISTÉRIO DA CIDADANIA, Art. $4^{\circ}$ ) e o gestor da política de assistência social deve promover, ao fim da situação de Emergência em Saúde Pública de Importância Nacional, "a gradativa desmobilização das ações socioassistenciais, implantadas ou reorganizadas no escopo desta Portaria” (PORTARIA No 369/2020, MINISTÉRIO DA CIDADANIA, Art. $10^{\circ}$ ).

As alusões em tela, quanto à forma de operacionalização do recurso para medidas de contingenciamento e enfrentamento à pandemia no âmbito do SUAS, podem parecer desnecessárias, mas elas ajudam a evidenciar o caráter truncado, burocrático, restritivo e emergencial dos investimentos do Estado brasileiro na política de assistência social. Quando afirmamos esse caráter emergencial não desmerecemos a importância de ações desse tipo, mas o caráter permanentemente improvisado dos mecanismos incipientes de proteção social.

O caráter pontual do investimento fica ainda mais claro se observarmos que não há recomposição do orçamento federal para Função 08 - assistência social -, que se encontra defasado em cerca de $\mathrm{R} \$ 1,3$ bilhões de reais. Este é ponto nodal da questão: o SUAS já padecia de um forte desfinanciamento e desmonte. Desde 2016, a política de assistência social perde recursos, o que vem se intensificando face ao contexto de endurecimento do ajuste fiscal, sobretudo em função da Emenda Constitucional 95 e da política de austeridade endurecida defendida e implantada pelo governo Bolsonaro.

O SUAS sempre viveu sob a disputa de diferentes direções sociais. Não há como desprezar os avanços alcançados sob os governos petistas, com a consolidação do marco normativo, da institucionalidade capilarizada em todo território nacional, tendo adesão dos 5.571 municípios brasileiros mais o DF e os 26 estados (LOPES; RIZZOTTI, 2020). Mesmo assim, sempre houve tensionamentos constantes na garantia de recursos para efetivar a rede socioassistencial, concorrendo com a modalidade de programa focalizado mais compatível com o capitalismo contemporâneo: os programas de transferência de renda.

Assim, os equipamentos sociais públicos e da rede conveniada sempre padeceram de problemas sérios. Entre estruturas precárias e recursos humanos limitados (cujas relações e condições de trabalho são em sua maioria extremamente precarizadas), o rol de elementos que balizam as condições físicas dos estabelecimentos, onde são realizadas as atividades e serviços socioassistenciais sempre imputaram grandes dificuldades à consolidação de uma rede pública de serviços de qualidade. Ambientes inadequados, condições de acessibilidade muito restritas, meios de comunicação e transporte restritos ou inexistentes, inexis- 
tência ou pífias condições para garantia de sigilo profissional para os profissionais de nível superior que gozam dessa prerrogativa, improvisação de instalações, sempre compuseram o leque das questões mais gritantes que abalizam a existência do SUAS.

Este quadro se aprofundou drasticamente nos últimos anos e mesmo os programas de transferência de renda - que desde 2004 recebem maior aporte de recursos federais no campo assistencial - tiveram queda de investimento. A PLOA para 2020, no que tange o Programa Bolsa Família (PBF), previa o atendimento de 13,2 milhões de famílias, uma redução de 400 mil famílias em relação a 2019. De acordo Neri (2020), em termos líquidos, cerca de 1,1 milhões de famílias foram desligadas do Programa entre maio de 2019 e janeiro de 2020. Segundo Paiva (et al, 2020), o PBF possui uma fila estimada de aproximadamente 1,7 milhão de famílias.

A ingerência do governo federal no enfrentamento à crise sanitária e as manifestações da tragédia social que ela vem deflagrando ocupam lugar de destaque no cenário mundial. Mesmo o auxílio emergencial - medida que não só contribuiria para garantia da sobrevivência de trabalhadores informais e Microempreendedores Individuais (MEIs) - como poderia garantir certo potencial de consumo interno - foi ostensivamente dificultado pelo governo federal. Desde a proposição do valor irrisório de $\mathrm{R} \$ 200,00$, derrubado pela mobilização da oposição que garantiu um benefício no valor de $\mathrm{R} \$ 600,00$, à operacionalização ineficiente, retardatária e nebulosa, o governo demonstra sua completa incompetência técnica e desprezo às demandas sociais.

O governo optou por um caminho que desprezou o aparato institucional do próprio SUAS, o know-how do sistema de informação que gerencia a base de dados do Cadastro Único, criando um novo sistema paralelo, confuso e ineficiente, que privilegiou o uso de dispositivos celulares, via internet, para requisição. Tal estratégia potencializou a exclusão de vários segmentos de trabalhadores, como pessoas em situação de rua e população periférica, boa parte deles sem CPF ativo, que é condição para liberação do benefício. Por outro lado, des considerou que importante parcela do público a ser beneficiado não tem celular ou acesso à internet, sem contar na impossibilidade de operacionalizar um aplicativo por não saber lidar com esse tipo de tecnologia.

Ainda que o governo não tenha recorrido aos serviços socioassistenciais para compor a rede de operacionalização de garantia de acesso ao benefício, as dificuldades de acesso, as informações truncadas e o próprio referenciamento que a população tem nos CRAS e CREAS também convergiram para intensi- 
ficação de demandas por orientação, informação e até mesmo auxílio na solicitação do benefício. Cenário este que agravou as condições já precárias e infladas de demandas e trabalho profissional no SUAS.

\section{Dilemas e resistências do exercício profissional de assis- tentes sociais no SUAS no contexto do novo Coronavírus no estado do Rio de Janeiro}

Cabe inicialmente destacar que a pandemia do novo Coronavírus, ainda que afete o conjunto da sociedade, não homogeneíza a forma pela qual as diferentes classes sociais a vivenciam e enfrentam. Ademais, crises sanitárias dessas proporções têm potencial de descortinar e acentuar contradições inerentes ao sistema capitalista (desigualdade social, fome, miséria, desemprego, violência, entre outras), sobre as quais a categoria profissional de assistentes sociais já possui um acúmulo teórico-metodológico, técnico-operativo e ético-político para atuar.

Neste contexto, é imprescindível o engajamento profissional na defesa intransigente, em especial de um princípio fundamental do Código de Ética Profissional: "o compromisso com a qualidade dos serviços prestados à população e com o aprimoramento intelectual, na perspectiva da competência profissional" (CFESS, 2011, p. 24 ), a fim de uma melhor qualificação para atuar com os (as) usuários (as) da política de Assistência Social, haja vista a complexificação das demandas apresentadas e o contexto de avanço do conservadorismo por dentro do SUAS no estado do Rio de Janeiro, com "velhas" demandas da referida política apresentadas com uma "nova roupagem", sob o discurso humanitário de solidariedade e de união de esforços, de que "estamos todos no mesmo barco".

Ao observarmos os relatos sobre a situação de municípios do Rio de Janeiro, em março de 2020, referentes à atuação nos equipamentos da Assistência Social, extraídos da Nota do Fórum Estadual dos Trabalhadores do SUAS (FETSUAS) - RJ sobre o trabalho na política de Assistência Social e a pandemia da COVID-19, é possível conferir condições que já precarizavam seus serviços e benefícios anteriormente, e são agravadas pelas novas contradições que se colocam diante da crise sanitária, social e econômica no país advindas com a pandemia. 
De acordo com o documento, os serviços socioassistenciais têm funcionado de maneira presencial, alguns de maneira remota no período em questão, mas não há um plano de contingência, orientações ou protocolos de funcionamento, informações consistentes por parte das gestões ou condições mínimas de segurança para prevenção do contágio pela COVID-19.

Além disso, de acordo com os relatos dos (as) trabalhadores (as) presentes na reunião do FETSUAS/RJ, na maioria dos municípios, não havia regulamentação e/ou efetivação de benefícios eventuais, tampouco havia articulações consistentes com outras políticas setoriais.

$\mathrm{Na}$ maioria dos municípios, sobre os quais obtiveram relatos, os equipamentos de proteção individuais (EPI's), bem como, produtos higiênicos para usuários (as) e trabalhadores (as) não estavam sendo fornecidos, e, quando fornecidos, foram entregues tardiamente e em quantidade insuficiente. Houve caso de município em que sequer fora fornecido sabão para lavagem das mãos por parte de profissionais e usuários (as), indo de encontro com a Portaria $\mathrm{n}^{\circ}$ 337/2020 do Ministério da Cidadania e Orientações do Ministério Público do Trabalho, que regula as medidas para o enfrentamento da situação de emergência de saúde pública decorrente do Novo Coronavírus pelo SUAS, especialmente do que trata em seu artigo $3^{\circ}$.

Em todos os relatos, avaliou-se não ter havido a devida capacitação de trabalhadores (as) quanto ao uso e manejo dos EPI's e medidas de prevenção de riscos relacionadas ao contágio pela COVID-19, contrariando-se orientação dos mais diversos órgãos, como o Ministério Público do Trabalho e o próprio Ministério da Cidadania.

No que se refere à adoção de turnos de revezamento para promover melhor distribuição da força de trabalho com o objetivo de evitar a concentração e a proximidade de pessoas no ambiente de trabalho, na maioria dos relatos, pode-se depreender que houve liberação do trabalho ou para trabalho de maneira remota de pessoas dos grupos de risco anunciados pela Organização Mundial de Saúde (OMS) e pelo Ministério da Saúde (MS). Na maioria dos relatos, constatou-se a presença de algum tipo de rodízio entre profissionais nos equipamentos ou redução dos horários de funcionamento e, em alguns, houve a possibilidade de teletrabalho, compreendendo este momento como de excepcionalidade.

Contudo, as orientações de funcionamento por parte das gestões parecem não ser consistentes e seguir qualquer tipo de planejamento ou preocupação com subsídios para ofertas ao público atendido. Houve também relatos de 
coexistência de formas divergentes de gestão do trabalho, imputando condicionantes diferenciados para a realização do trabalho a depender do vínculo de contratação. Disso, são ilustrativos fatos notificados ao FETSUAS, no que tange à garantia de seguranças básicas como trabalho por escala para servidores públicos estatutários e a intensificação da carga horária para aqueles em regime de trabalho por contrato temporários e/ou cargos comissionados.

Os (as) trabalhadores consideram que algumas das interferências realizadas pela gestão dos municípios estão relacionadas ao fato de ser ano eleitoral, onde se percebe uma tentativa de assistencialização da política em prol de finalidades eleitoreiras. Inclusive, houve relatos sobre municípios em que se estava "obrigando" trabalhadores (as) a distribuir cestas básicas sem nenhum tipo de equipamento de proteção individual sob a justificativa de serem "visitas domiciliares". Nestes casos, observou-se também que se feria a autonomia técnica de algumas categorias que têm na visita domiciliar um instrumento técnico e que deve ser escolhido de acordo com a avaliação específica, como no caso de assis tentes sociais, por exemplo.

O uso político-eleitoral da política de assistência social nestes termos remota para o caldo cultural do coronelismo, cujas reticências são ainda corrosivas em alguns municípios, sobretudo os de pequeno porte, mas não exclusivamente, haja vista o município do Rio de Janeiro. Em um contexto que já vinha sendo marcado pela deslegitimação e desrespeito a institucionalidade democrática por parte do governo federal, ${ }^{3}$ e da adoção de uma direção social contrária à cultura de direitos, tais processos tornam-se cada vez mais potencializados de uma alavancada reacionária nos serviços socioassistenciais.

Destacou-se também uma postura mais autoritária por parte de alguns gestores (as) da Assistência Social, o que só faz agravar os desafios a serem empreendidos pela organização de trabalhadores (as) e usuários (as) neste momento. Entretanto, não se trata de uma postura que ocorre em todos os municípios.

Em relação à infraestrutura, os (as) trabalhadores (as) identificaram que os equipamentos da assistência social que já vinham sendo precarizados e suca-

\footnotetext{
${ }^{3}$ É elucidativo o desmonte dos conselhos de direitos e a banalização do controle social perpetrada pelo governo Federal como a não convocação da Conferência Nacional de Assistência Social pelo Conselho Nacional de Assistência Social e o fato do governo federal não ter viabilizado as condições para realização da instância nacional de deliberação deste campo. Vale ressaltar, no entanto, que há luta coletiva pelo SUAS e pelo controle social e a construção coletiva da Conferência Nacional Democrática de Assistência Social, organizada e realizada por diversos atores como coletivos profissionais, de usuários, fóruns de trabalhadores e representantes da sociedade civil, nos dias 25 e 26 de novembro de 2019, em Brasília, é expressão de que essa luta está viva.
} 
teados, ganharam amplificação durante a pandemia, dada a diminuição de recursos voltados para a execução da política. Muitos locais de trabalho e atendimento que já eram insalubres antes da pandemia, cuja infraestrutura fragilizada e inadequada dos equipamentos - que já existiam sem ventilação, janelas incompatíveis, sem acesso à internet - aparecem mais agravadas com a pandemia. Isso deixa os (as) profissionais sem suporte para atender às demandas dos (as) usuários (as) do serviço.

Outra dificuldade apontada foi a de locomoção, uma vez que diversas linhas de transporte intermunicipal não estavam funcionando.

Diante do exposto, há que se destacar as nuances que estão por trás do apelo à solidariedade num contexto pandêmico de exceção, no qual há um solo fértil para a intensificação da polivalência do trabalhador, assim como, para a tendência à desprofissionalização e desespecialização da categoria de assistentes sociais. Dessa forma, é estratégica e essencial a defesa das competências e atribuições privativas profissionais previstas nos artigos $4^{\circ}$ e $5^{\circ}$ da Lei 8.662/93 (CFESS, 2011), respectivamente.

Importante também sinalizar a diferença significativa entre o controle social de viés participativo e democrático, que contempla uma das bandeiras de luta de assistentes sociais e o controle do social por parte do Estado cada vez mais autoritário, através de ações policialescas e caritativas, que a Política de Assistência Social atravessada pelo avanço do conservadorismo reacionário vem buscando realizar, sendo neste contexto, de suma relevância para os enfrentamentos e resistências necessários, ter em vista a correlação de forças de cada espaço sócio-ocupacional, os vínculos fragilizados existentes e uma análise territorial do mesmo, onde há espaços com maiores tensionamentos do que os outros.

Para exemplificar o avanço do conservadorismo reacionário no SUAS, analisemos o caso do município do Rio de Janeiro (Gestão Plena) ${ }^{4}$ com relação ao trabalho com pessoas em situação de rua. Durante este cenário de pandemia, retornaram as ações chamadas de "abordagens intersetoriais" ou "ações conjuntas", que dizem respeito a atividades de cunho de "limpeza urbana" e políti-

\footnotetext{
4 A saber, no caso da gestão municipal e do Distrito Federal, são possíveis três níveis de habilitação ao SUAS: inicial, básica e plena. A gestão inicial fica por conta dos municípios que atendam a requisitos mínimos, como a existência e funcionamento de conselho, fundo e planos municipais de assistência social, além da execução das ações da Proteção Social Básica com recursos próprios. No nível básico, o município assume, com autonomia, a gestão da proteção social básica. No nível pleno, ele passa à gestão total dasações socioassistenciais (Fonte: Ministério da Cidadania).
} 
co-partidário, envolvendo a Polícia Militar, a Guarda Municipal, a Companhia Municipal de Limpeza Urbana (COMLURB), as Superintendências Regionais e profissionais do SUAS, dentre eles, assistentes sociais, com o falso discurso de que estes últimos estão presentes para garantirem que não haja nenhuma violação de direito nestas ações.

Tais atuações conjuntas, entretanto, prejudicam bastante o trabalho da abordagem processual realizada pelas equipes dos Centros de Referência Especializado de Assistência Social (CREAS), como também desgastam e fragilizam os vínculos estabelecidos entre as equipes e os (as) usuários (as) em situação de rua destes territórios.

É válido sinalizar ainda que não há ingenuidade em nenhum conceito, assim, faz-se necessária uma reflexão acerca dos conceitos de vulnerabilidade, risco e exclusão social, dispostos na Política Nacional de Assistência Social (BRASIL, PNAS/2004) e no Sistema Único de Assistência Social (BRASIL, NOB-SUAS/2005), sendo importante buscar desvelar os princípios sustentadores dos mesmos e compreender a direção social que eles apontam, de transformação ou de manutenção da realidade.

Assim, concernente à Política de Assistência Social, analisando criticamente o que os conceitos de vulnerabilidade, risco e exclusão possuem em comum, chega-se a uma perspectiva reacionária, culpabilizando o indivíduo pela sua situação, desvinculando as suas problemáticas de um contexto estrutural, balizadores do sistema capitalista.

No que tange à referida política pública, no sentido de resistência a essas tendências de desmonte do SUAS, há que se ressaltar a importância das deliberações e bandeiras de luta do Conjunto CFESS-CRESS: defesa da Assistência Social como direito e do SUAS como política pública e as condições de trabalho dos/as assistentes sociais e demais trabalhadores/as; articulação com outras categorias profissionais, por meio da inserção no fórum de trabalhadores/ as do SUAS, nos espaços de controle social e das organizações políticas de trabalhadores/as para defesa da gestão do trabalho, e incidência nas mesas de negociação; repúdio ao primeiro-damismo na política de assistência social e recusa de práticas assistencialistas, que reproduzem a lógica do favor em detrimento dos direitos; defesa do SUAS 100\% estatal, universal e de qualidade, com base nos princípios da proteção social; defesa de que o Benefício de Prestação Continuada (BPC), bem como, doações de natureza provisória, não sejam computados no cálculo da renda familiar, para efeito do acesso aos programas de transferência de renda e que a renda per capita seja de um salário mínimo; defesa da 
extinção das condicionalidades dos/as usuários/as e famílias beneficiárias dos programas de transferência de renda; participar dos espaços de discussão do orçamento público e financiamento de políticas públicas, tendo em vista a aprovação da EC 95/2016 (CFESS, 2018).

É de grande valia salientar aqui o trabalho que vem sendo realizado pelo "Conjunto CFESS-CRESS: ações em defesa da vida", para defender a profissão e o trabalho profissional, visto que o Serviço Social está na linha de frente de atuação contra o Novo Coronavírus, em conjunto com outras profissões em todo o Brasil. Entretanto, apesar de estar disposto no artigo 3, inciso d, do Código de Ética do/a Assistente Social: "participar de programas de socorro à população em situação de calamidade pública, no atendimento e defesa de seus interesses e necessidades" (CFESS, 2011, p.27), é essencial destacar que a categoria de assistentes sociais não é composta por heroínas e heróis, mas é classe trabalhadora e, enquanto tal, faz-se necessária a luta coletiva com outras instâncias, órgãos e movimentos sociais, a fim de ter garantidas as condições étnicas e técnicas para o exercício profissional protegido, qualificado e compromissado. Vale destacar, a expedição de normativas e resoluções neste contexto, no intuito de subsidiarem o trabalho de assistentes sociais, advindas de debates por meio das Comissões de Orientação e Fiscalização (COFI'S) e das assessorias jurídicas do Conjunto, baseando-se em orientações de autoridades sanitárias com respaldo científico, em prol de ações para defender a profissão, o trabalho e a vida.

\section{Considerações finais}

Vale salientar que esta pandemia está servindo, dentre tantas coisas, para dar transparência, para a sociedade em geral, das principais mazelas produzidas pelo sistema capitalista, precipuamente, num país capitalista dependente marcado por uma profunda e histórica desigualdade social, além de provar a duros golpes à mesma e aos seus governantes de que as principais "armas" para vencer esta "guerra", são aqueles (as) que vêm sendo tão atacados (as) e desvalorizados (as) pelo Poder Público na contemporaneidade brasileira: o SUS; a Ciência; a Educação (em especial, as Universidades Públicas); a Arte; a Cultura; o SUAS.

É de grande valia pontuar que, apesar dos aparelhos midiáticos tentarem repassar um ideário de que "estamos todos no mesmo barco", certamente 
não estamos, haja vista a realidade da maioria dos (as) usuários (as) da política de Assistência Social. Em suma, estamos falando do "risco de não poder enfrentar os riscos" (parte do título da live realizada em 16/04/20 pela Associação Nacional de Ensino e Pesquisa do Campo de Públicas - ANEPCP). Se a "vacina" atual é o distanciamento/isolamento social, o chamamento ao "fica em casa", imaginem como estão ainda mais desprotegidas estas pessoas, em especial, a população em situação de rua nesta conjuntura.

Assim, ficar em casa e ter uma casa para cumprir a orientação crucial das autoridades e órgãos sanitários para diminuir a velocidade da propagação do vírus neste tempo de pandemia, de fato, são privilégios de classe, dos quais, os (as) usuários (as) da Assistência Social, sobretudo, pessoas que utilizam as ruas como espaço de moradia e/ou sobrevivência não possuem. Dessa forma, medidas de distanciamento, isolamento social e quarentena não podem ser desassociadas de medidas de proteção social, senão as classes menos favorecidas sofrerão muito mais os impactos desta pandemia. Não podemos continuar naturalizando a tragédia social vivida, não podemos voltar "ao normal”, visto que este é a essência do problema. De fato, "a luta de classes não vai acabar por causa do coronavírus, mas a gente pode mitigá-la" (fala do Sociólogo e Professor Doutor da UERJ Dario Souza e Silva durante a live "População de rua e COVID19", em 15/04/20).

Além disso, faz-se essencial buscar romper com a herança conservadora da identidade dos usuários (as) do SUAS, que são estigmatizados (as) de desorganizados (as), despolitizados (as) e disponíveis para manobras eleitorais. São necessários também: refletir sobre a ausência do debate da classe social na política de Assistência Social e problematizar os conceitos de vulnerabilidade e risco social contidos na mesma (COUTO; YAZBEK E RAICHELIS, 2014). Destaque ainda para a importância de se coletivizar a luta do SUAS para além do âmbito do Serviço Social, almejando a classe trabalhadora da política de Assistência Social, com ênfase na sua politização e criticidade para ultrapassar a herança supracitada.

É importante frisar que, na contemporaneidade pandêmica, o papel do Estado tem sido clamado a garantir formas de propriedade e novos nichos de mercantilização que gerem um grau de exploração de tal ordem, que solapa as condições mínimas de existência, por meio da expropriação dos meios de vida destruindo direitos sociais. É nesse sentido que o Estado tem encontrado uma nova articulação orgânica entre a repressão à classe trabalhadora e as formas as sistenciais conservadoras, dirigidas ao enfrentamento da "questão social" no ca- 
pitalismo dependente brasileiro, medidas reeditadas diante da crise que atravessamos desde 2008, aprofundadas a partir do golpe de 2016, com o esgotamento do ciclo neoliberal aliado ao projeto de conciliação de classes.

Ficam evidenciados, dessa forma, o caráter conservador da assistência social e a sua funcionalidade na reprodução da classe trabalhadora para a manutenção do status quo, sendo programas assistenciais e benefícios eventuais, como o caso do Auxílio Emergencial durante a pandemia da COVID-19, estratégias úteis do capital para regular o mercado a baixo custo, ficando seus usuários "reféns" da sua lógica minimalista de direitos.

Nesse sentido, torna-se fundamental que a categoria de assistentes sociais siga na defesa das bandeiras de lutas do conjunto CFESS-CRESS, dentre as quais, ressaltar a valorização do SUAS e do SUS, com inspiração no Princípio Fundamental II do Código de Ética Profissional: "defesa intransigente dos direitos humanos e recusa do arbítrio e do autoritarismo" (CFESS, 2018), sob a égide do projeto ético-político profissional comprometido com a emancipação humana.

\section{Referências}

ANTUNES, R. Como se trama a uberização total. Publicado no site Le Monde Diplomatique Brasil em 09/06/2020. Disponível em: <https://outraspalavras.net/outrasmidias/como-se-trama-a-uberizacao-total/>. Acesso em: 09 jan. 2021.

BRASIL. Decreto nº 10.282/2020. Presidência da República: Brasília, 2020. Disponível em: < http://www.planalto.gov.br/ccivil_03/_ato2019_ 2022/2020/decreto/D10282.htm\#: :text=D10282\&text=Regulamenta\%20a $\% 20 \mathrm{Lei} \% 20 \mathrm{n} \% \mathrm{C} 2 \% \mathrm{BA} \% 2013.979, \mathrm{p} \% \mathrm{C} 3 \%$ BAblicos $\% 20 \mathrm{e} \% 20$ as $\% 20$ atividades $\% 20$ essenciais.\&text=Objeto-,Art.,p\%C3\%BAblicos\%20e\%20as\%20atividades \%20essenciais>. Acesso em: 09 jan. 2021.

. Medida Provisória No 953. Diário oficial da união. Publicado em: 16/04/2020, Edição: 73, Seção: 1, Página: 4. Brasília, 2020.

. Política Nacional de Assistência Social (PNAS). Ministério do Desenvolvimento Social e Combate à Fome (MDS): Brasília, 2004.

. Política Nacional de Assistência Social (PNAS). Norma Operacional Básica (NOB/SUAS). Ministério do Desenvolvimento Social e Combate à Fome (MDS): Brasília, 2005. 
, Norma Operacional Básica de Recursos Humanos do Sistema Único de Assistência Social - NOB/RH - SUAS. Ministério do Desenvolvimento Social e Combate à Fome (MDS): Brasília, 2006.

BRAZ, M. O golpe nas ilusões democráticas e a ascensão do conservadorismo reacionário. Serviço Social e Sociedade, São Paulo, n. 128, p. 85-103, jan./ abr. 2017.

CASTELO, R. Supremacia rentista no Brasil neoliberal e a violência como potência econômica. Universidade e Sociedade, Brasília, ano XXVII, n. 60, jul. 2017, p.58-71.

Conselho Federal de Serviço Social - CFESS. Bandeiras de Lutas do Conjunto CFESS/CRESS. Brasília: CFESS, 2018.

Código de Ética Profissional. Lei de Regulamentação da Profissão, n. 8662. $9^{a}$ Edição. Brasília: Conselho Federal de Serviço Social, 2011. Disponível em:<http://www.cfess.org.br/arquivos/CEP2011_CFESS.pdf> . Acesso em: 10 jan. 2021.

COUTO, B. R.; YAZBEK, M. C.; RAICHELIS, R. A Política Nacional de Assistência Social e o Suas: apresentando e problematizando fundamentos e conceitos. In: COUTO, B.R. [et al.]. 4. ed. O Sistema Único de Assistência Social no Brasil: uma realidade em movimento. São Paulo: Cortez, 2014, p.32-65. FÓRUM ESTADUAL DE TRABALHADORES DO SUAS/RJ (FETSUAS/ RJ). Nota do FETSUAS-RJ sobre o trabalho na política de assistência social e a pandemia do COVID-19. Rio de Janeiro: FETSUAS/RJ, 2020. Disponível em: <https:// fetsuasriodejaneir.wixsite.com/website/post/trabalhadores-as-do-suas-e-epidemia-por-covid-19-acesse-documentos-importantes $>$ . Acesso em: 09 jan. 2021.

GOUVÊA, M. M. A culpa da crise não é do vírus. In: MOREIRA, E.; GOUVEIA, R. [et al] (orgs). Em tempos de pandemia: propostas para defesa da vida e dos direitos sociais. Rio de Janeiro: UFRJ, 2020.

GUERRA, Y. A formação profissional frente aos desafios da intervenção e das atuais configurações do ensino público, privado e à distância. Serviço Social e Sociedade, São Paulo, n. 104, out./dez. 2010, p.715-736.

HOEVELLER, R. A direita transnacional em perspectiva histórica: o sentido da "nova direita" brasileira. IN: DEMIER, F; HOEVELLER, R. (orgs.) A onda conservadora. Ensaios sobre os atuais tempos sombrios no Brasil. Rio de Janeiro: Mauad, 2016. 
IASI, M. De onde vem o conservadorismo? Blog da Boitempo. Publicado em 15/04/2015 Disponível em: < https://blogdaboitempo.com.br/2015/04/15/ de-onde-vem-o-conservadorismo/ > . Acesso em: 09 jan. 2021.

LOPES, M. H. C.; RIZZOTTI, M. L. A. Covid19 e proteção social: a contribuição do Sistema Único de Assistência Social - SUAS. In: CASTRO, D.; DAL SENO, D.; POCHMANN, M. Capitalismo e a Covid-19: um debate urgente. São Paulo: 2020.

LOWY, M. Conservadorismo e extrema direita na Europa e no Brasil. Serviço Social e Sociedade, São Paulo, n. 124, p. 652-664, out./dez. 2015.

MARX, K. O capital - Livro 1. São Paulo: Boitempo, 2013.

MINISTÉRIO DA CIDADANIA. Portaria Conjunta No 1 /2020. Brasília:

Ministério da Cidadania, 2020. Disponível em: $<$ http://blog.mds.gov.br/redesuas/portaria-conjunta-no-1-de-2-de-abril-de-2020/> . Acesso em: 09 jan. 2021.

Portaria $\mathrm{N}^{\mathrm{o}} 369 / 29$ de abril de 2020. Dispõe acerca do atendimento do Cadastro Único para Programas Sociais do Governo Federal. Diário Oficial da União. Publicado em: 30/04/2020, Edição: 82, Seção: 1, Página: 17. Ministério da Cidadania/Gabinete do Ministro: Brasília, 2020. Disponível em:

$<$ https://www.in.gov.br/en/web/dou/-/portaria-n-369-de-29-de-abril-de2020-254678622>. Acesso em: 09 jan. 2021.

MINISTÉRIO DA SAÚDE. Portaria $\mathbf{N}^{\circ}$ 337. Diário Oficial da União. Publicado em: 13/05/2020, Edição: 90, Seção: 1, Página: 116. Órgão: Ministério da Saúde/Secretaria Executiva: Brasília, 2020.

NERI, M. FGV Social comenta os cortes no Bolsa Família e o aumento da extrema pobreza no Brasil. Publicado em 03/03/2020 por Fundação Getúlio Vargas. Centro de Políticas Sociais. Disponível em: < https://cps.fgv.br/ destaques/fgv-social-comenta-os-cortes-no-bolsa-familia-e-O-aumentoda-extrema-pobreza-no-brasil>. Acesso em: 09 jan. 2021.

PAIVA, L. H.; SOUZA, P. H. G. F. de; BARTHOLO, L.; SOARES, S. Evitando a Pandemia da pobreza: possibilidades para o Programa Bolsa Família e para o Cadastro Único em resposta à Covid-19. Nota Técnica/Instituto de Pesquisa Econômica Aplicada (IPEA). Instituto de Pesquisa Econômica Aplicada (IPEA): Brasília, 2020. Disponível em:<http://repositorio.ipea.gov.br/ handle/11058/9826>. Acesso em: 09 jan. 2021 . 
POGGI, T. Fascismo à brasileira. In: CISLAGHI, J. F.; DEMIER, F. (orgs.). $\mathbf{O}$ neofascismo no poder (ano 1): análises críticas sobre o governo Bolsonaro. Rio de Janeiro: Conseqüência, 2019.

ESCORSIM NETTO, L. O conservadorismo clássico: elementos de caracterização e crítica. São Paulo: Cortez, 2011.

SILVA, M. M. Sistema Único de Assistência Social: entre o desmonte e a condição de serviço essencial. In: MOREIRA, E.; GOUVEIA, R. [et al]. Em tempos de pandemia: propostas para defesa da vida e dos direitos sociais. Rio de Janeiro: UFRJ, 2020.

SILVA, R. R. da; MAURIEL, A. P. O. Educação permanente na política de assistência social: uma experiência de extensão universitária. In: CONGRESSO BRASILEIRO DE ASSISTENTES SOCIAIS, 2019, v. 16 n. 1 (2019): Congresso Brasileiro de Assistentes Sociais. Anais. Brasília: CFESS, 2019 . Disponível em: <https://broseguini.bonino.com.br/ojs/index.php/CBAS/article/view/ 1038>. Acesso em: 09 jan. 2021.

SILVEIRA JÚNIOR, A. A. A assistência social e as ideologias do social-liberalismo: tendências político-pedagógicas para a formação dos trabalhadores do SUAS. 2016. Tese (Doutorado em Serviço Social) - Programa de Pós-Graduação em Serviço Social, Universidade Federal de Pernambuco, Recife/PE, 2016, 358 folhas.

YAZBEK, M. C. Educação permanente e a política de assistência social: o papel da academia e os desafios para o Serviço Social. In: CRUS, J. F. da; ALBUQUERQUE, S. A.(Orgs.). et al. Gestão do Trabalho e Educação Permanente do SUAS em Pauta. Brasília: MDS, 2014, p.129-142. 